Disclosure of Interests: None declared

DOI: 10.1136/annrheumdis-2019-eular.7530

\section{AB0460 USE OF PLATELET RICH PLASMA (PRP) IN TREATMENT OF DRY EYE SYNDROME IN THE PATIENTS WITH SJÖGREN SYNDROME: PRELIMINARY RESULTS}

Annunziata Capacci ${ }^{1}$, Francesco Ricci ${ }^{2}$, Valentina Varriano ${ }^{3}$, Barbara Tolusso ${ }^{1}$, Pietro Rubortone ${ }^{3}$, Anna Maria Paglionico ${ }^{1}$, Antonio Ciardiello ${ }^{2,4}$,

Stefano Alivernini ${ }^{1,3}$, Gianfranco Ferraccioli ${ }^{3}$, Elisa Gremese ${ }^{1,3}{ }^{1}{ }^{1}$ Fondazione

Policlinico Universitario A. Gemelli IRCCS, Division of Rheumatology, Rome, Italy;

${ }^{2}$ Fondazione Policlinico Universitario A.Gemelli IRCCS, Division of Ophthalmology, Rome, Italy; ${ }^{3}$ Università Cattolica del Sacro Cuore, Division of Rheumatology, Rome, Italy; ${ }^{4}$ Università Cattolica del Sacro Cuore, Division of Ophthalmology, Rome, Italy

Background: Xeroftalmia and xerostomia are the hinge symptoms of Sjögren Syndrome and often they negatively influence patients' quality of life. The eyewashes use based on Platelet Rich Plasma (PRP) has been applicate in the treatment of the xeroftalmia, both primitive and secondary.

Objectives: To evaluate the effect of subconjunctival injections and PRP based eyewashes on the ocular dryness (subjective and objective) in patients suffering of primary Sjögren syndrome (pSS).

Methods: Six pSS patients ( 6 females, age at the beginning $48.2 \pm 9.7$ years) have been recruited in the study. All patients were reaching the criteria for pSS diagnosis; for each patient clinical and immunological data have been recorded. Patients with Schirmer Test value, in at least an eye, inferior to $10 \mathrm{~mm}$ after 5 minutes, and suffering from severe dryness calculated by OSDI score (between 33 and 100, severe condition of dry eye) in spite of therapies with tear substitutes were selected. The OSDI (Ocular Surface Index) is a questionnaire for the evaluation of the subjective ocular dryness. Selected patients have been addressed to treatment with PRP. The PRP is constituted by human plasma enriched with plaques by means of the utilisation of a special kit, therefore each patient has been subjected to a blood drawing, from which PRP has been extracted. Of this, a part has been injected in subconjunctival seat; from remained one, an eyewash has been extracted that the patients have assumed 6 times in the day up to exhaustion (about 5 days) during which another topic therapy was not used. The patients have been valued to the basal time and after ten days of the procedure; besides follow-up visits each three months are scheduled. To each evaluation Schirmer Test data and OSDI have been checked.

Results: Each patient had severe xeroftalmy, evaluated by Schirmer Test (right Eye: $3.33 \pm 2.66$; left eye: $6.83 \pm 6.5$ ) and index OSDI (59.71 \pm 20.72 ). All the patients had Schirmer Test values, in at least an eye, lesser than $10 \mathrm{~mm}$ after 5 minutes. The analized cohort had homogeneous clinical characteristics (presence of xerostomy and absence of inflammatory indexes, hypergammaglobulinemia, arthritis and linfoadenomegaly). After one week (T1), OSDI values were significantly more reduced compared to the basal time $(38.89 \pm 15.12 ; p=0.028)$. The Schirmer Test values were not significative different to the follow-up visit compared to the basal one. No patients presented pre- and post-procedural complications, neither related infectious events. At 3 months follow up after first treatment (T2) no statistically significant difference in OD/OS Schirmer test values and OSDI score compared to the basal time were observed.

Conclusion: The use of PRP in dry eye syndrome in patients with Sjögren syndrome seems to be effective in alleviating symptoms and improving patients' life quality. Is need further follow-up to confirm data, to value effect also on the objective tests and to evaluate necessity of repeating treatment.

\section{REFERENCES}

[1] ShiboskiSC;Arthritis Care Res, 2012; 64(4): 475-487

[2] AlioJ; OphtalmicResearch, 2017; 39: 124-129

[3] AlioJ; CurrPharm Biotech, 2012; 13: 1257-1265

Disclosure of Interests: Annunziata Capacci: None declared, Francesco Ricci: None declared, Valentina Varriano: None declared, Barbara Tolusso: None declared, Pietro Rubortone: None declared, Anna Maria Paglionico: None declared, Antonio Ciardiello: None declared, Stefano Alivernini Speakers bureau: BMS, Gianfranco Ferraccioli Speakers bureau: BMS, Roche, Elisa Gremese Consultant for: AbbVie, BMS, Celgene, Janssen, Lilly, MSD, Novartis, Sanofi, UCB, Roche, and Pfizer, Speakers bureau: BMS, Speakers bureau: Roche, Speakers bureau: AbbVie, BMS, Celgene, Janssen, Lilly, MSD, Novartis, Sanofi, UCB, Roche, and Pfizer DOI: 10.1136/annrheumdis-2019-eular.7397

\section{\begin{tabular}{|l|l}
\hline AB0461 BELATACEPT IN SLE KIDNEY TRANSPLANT PATIENTS & PATI
\end{tabular}}

Irene Carrión Barberà ${ }^{1}$, Melissa Fajardo², Demetra Tsapepas ${ }^{2}$, Hilda Fernandez ${ }^{2}$, Anca Askanase ${ }^{3} .{ }^{1}$ Hospital del Mar, Rheumatology, Barcelona, Spain; ${ }^{2}$ Columbia University Medical Center, Nephrology, New York, United States of America; ${ }^{3}$ Columbia University Medical Center, Rheumatology, New York, United States of America

Background: Lupus nephritis (LN) results in the need for renal replacement therapy (RRT) in $10-30 \%$ of LN pts; of these $30 \%$ receive a kidney transplant (KT). Belatacept (bela) is a second-generation selective T-cell co-stimulator blocker (inhibits CTLA-4) used as an alternative to calcineurin inhibitors (CNI) for maintenance regimens after KT. The pathogenic relevance of CTLA-4 inhibition and the favorable cardiovascular profile of bela make it an attractive therapeutic option in SLE. Additionally, bela IV ensures therapeutic adherence.

Objectives: The current study was initiated to evaluate the effect of bela on graft function and extrarenal SLE.

Methods: This retrospective single-center study evaluates the outcomes of LN KT recipients treated with bela from 2006-2018 at the Columbia University Lupus and Renal Transplant Cohorts. The bela regimen was $5 \mathrm{mg} /$ $\mathrm{kg}$ every 2 weeks $\times 5$ doses, then monthly. CNI weaning among the bela group was not standardized. Immunosuppressive regimen, kidney allograft function, and SLE activity were examined.

Figure 1: Creatinine trend before and after bela

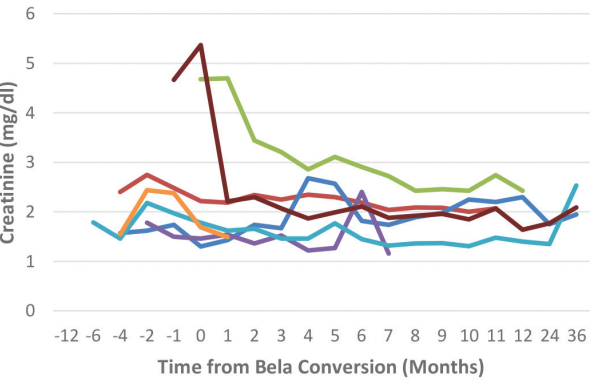

$\longrightarrow \mathrm{A}-\mathrm{B}-\mathrm{C} \longrightarrow \mathrm{D}-\mathrm{E}-\mathrm{F}-\mathrm{G}$

Figure 2: SLEDAI-2KG before and after bela

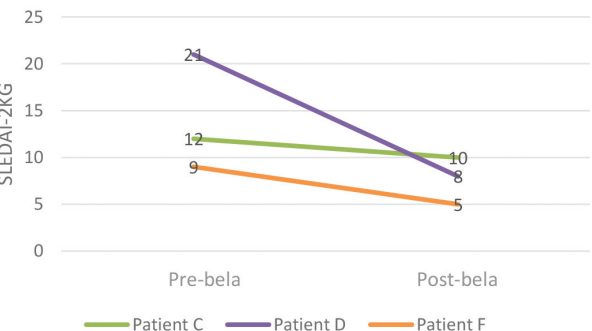

\begin{tabular}{|c|c|c|c|c|c|c|c|c|}
\hline 10 & $\begin{array}{l}\text { Age at } \\
\text { SLE dx }\end{array}$ & Race & $\begin{array}{l}\text { LN } \\
\text { class }\end{array}$ & $\begin{array}{l}\text { Time to } \\
\text { KT (yrs) }\end{array}$ & $\begin{array}{l}\text { Type } \\
\text { KT }\end{array}$ & Induction & $\begin{array}{l}\text { Reason for } \\
\text { conversion }\end{array}$ & $\begin{array}{l}\text { Immunosuppressive regimen } \\
\text { before conversion }\end{array}$ \\
\hline A & 16 & Black & $\mid \mathrm{V}, \mathrm{VI}$ & 13 & DDKT & ATG & Non-adherence & TAC, MMF \\
\hline B & 30 & Asian & & 2 & LRKT & ATG & $\begin{array}{l}\text { Mod IFTA \& } \\
\text { Arteriosclerosis }\end{array}$ & TAC, MPA, PRED \\
\hline c & 18 & White & $\mathrm{IV}, \mathrm{v}$ & 23 & DDKT & ATG & Cortical necrosis & CYC, MMF, PRED \\
\hline D & 19 & Black & v & 9 & LUKT & ATG & CNI side effects & TAC, MPA, PRED \\
\hline E & 22 & Asian & & 5 & LRKT & ATG & CNI side effects & TAC, MMF, PRED \\
\hline $\mathrm{F}$ & 18 & Black & v & 17 & DDKT & Alemtuzumab & CNI side effects & TAC, MMF, PRED \\
\hline G & 25 & $\begin{array}{l}\text { White } \\
\text { (Hispanic) }\end{array}$ & III, IV & 23 & DDKT & Basiliximab & TMA (biopsy) & TAC, MPA, PRED \\
\hline
\end{tabular}

Results: 48 pts with LN had undergone KT between 2006-2018 with follow-up time of $72.2 \pm 74.6$ months. Bela was started in 7 pts on $\mathrm{CNI}$ regimens (TAC $\mathrm{N}=6$, cyclosporine $\mathrm{N}=1$ ) at $15.5 \pm 17.1$ months after $\mathrm{KT}$. All pts were female, age at SLE diagnosis $21.1 \pm 4.9 \mathrm{yrs} ; 5$ had undergone RRT prior to KT (4 hemodialysis, 1 peritoneal dialysis) for $38.7 \pm$ 37.8 months. The interval between SLE diagnosis and KT was $13.1 \pm$ $8.3 \mathrm{yrs}$. At the time of bela initiation, all pts were also treated with prednisone $(7.1 \pm 2.7 \mathrm{mg} / \mathrm{day}), 6$ with mycophenolate $(1123 \pm 625 \mathrm{mg} / \mathrm{day})$, and 1 azathioprine (25mg/day). CNIs were continued in $5 / 7$ patients at 6 months after bela. 2 pts were on hydroxychloroquine, 2 took it only prior to $\mathrm{KT}$. In 5 patients, creatinine stabilized 6 months after bela, 1 returned to $\mathrm{HD}$ due to $\mathrm{CNI}$-toxicity and pyelonephritis and 1 is relisted for KT due to ACR and cortical necrosis (Fig. 1). No allograft failure due to recurrent 
LN was noted in any of the 7 pts. 5 pts are followed by Rheumatology for extrarenal SLE; no extrarenal manifestations are documented in the other 2. Data on SLE Disease Activity pre and post bela were available and scored in $3 / 5$ pts using the SLEDAI-2KG which accounts for clinical and laboratory manifestations, as well as steroid use (Fig. 2). Mean dsDNA pre and post bela was $133 \pm 178 \mathrm{Ul} / \mathrm{mL}$ and $58 \pm 72 \mathrm{Ul} / \mathrm{mL} ; \mathrm{C} 3$ $89 \pm 31 \mathrm{mg} / \mathrm{dL}$ pre and $91 \pm 21 \mathrm{mg} / \mathrm{dL}$ post; C4 $35 \pm 15 \mathrm{mg} / \mathrm{dL}$ pre and $38 \pm 7 \mathrm{mg} / \mathrm{dL}$ post.

Conclusion: Bela in LN KT recipients may decrease extrarenal manifestations, attenuate $\mathrm{CNI}$ toxicity and stabilize allograft function, providing a better alternative to $\mathrm{CNI}$ regimens. Furthermore, these data suggest that bela may be a therapeutic option in SLE.

\section{REFERENCES}

[1] Almaani, Salem, Alexa Meara, and Brad H. Rovin. Update on lupus nephritis. Clinical Journal of the American Society of Nephrology 12.5 (2017):825-835.

[2] Ortega, L. M., et al. Lupus nephritis: pathologic features, epidemiology and a guide to therapeutic decisions. Lupus 19.5 (2010):557-574.

[3] Sexton, Donal J., et al. ESRD from lupus nephritis in the United States, 1995-2010. Clinical Journal of the American Society of Nephrology 10.2 (2015):251-259.

Acknowledgement: We would like to thank KERN PHARMA laboratories for their support through "Becas FER-KERN PHARMA".

Disclosure of Interests: None declared

DOI: 10.1136/annrheumdis-2019-eular.626

\section{AB0462 IMMUNIZATIONTO RITUXIMAB IS MORE FREQUENT IN AUTOIMMUNE SYSTEMIC AUTOIMMUNE DISEASES THAN IN RHEUMATOID ARTHRITIS AND MAY BE MANAGED BY SWITCHING FROM RITUXIMAB TO OFATUMUMAB}

Alice Combier, Gaetane Nocturne, Julien Henry, Rakiba Belkhir, Stephane Pavy, Xavier Mariette, Raphaèle Seror. Bicetre Hospital AP-HP, Rheumatology, Le Kremlin-Bicêtre, France

Background: The most widely used B cell targeted therapies in autoimmune diseases (AID) is Rituximab (RTX), a murine chimeric monoclonal antibody. Among RTX's side effects, immunization and anti-drug antibodies to RTX (RTX-ADA) production have been reported but their consequences are poorly described. The immunization rate against RTX in rheumatoid arthritis (RA) is $2,7-9,2 \%$ and it seems to be higher in other sAID although data is lacking.

Objectives: We aimed to evaluate the frequency, consequences and predictive factors of RTX-ADA in RA and SAID, as well as the use of an alternative B-cell targeted therapy, ofatumumab (OFA) in case of RTX-ADA.

Methods: All patients with RA or SAID treated with RTX from 2012 to 2017 in our tertiary reference centre for SAID were retrospectively studied. Patients who were tested for RTX-ADA were identified. Clinical and biological characteristics of RTX immunized patients were compared to those of non-immunized patients. For patients treated with OFA, clinical and biological efficacy was obtained before and after treatment.

Results: 199 patients were treated with RTX (RA: 124, sAID: 75 including 38 primary Sjögren's Syndrome (pSS), 15 systemic lupus erythematous, 7 myositis, 6 overlap syndrome, 5 ANCA-associated vasculitides and 4 other sAID). Among the 62/199 (31.1\%) tested for RTX-ADA, 14 were positive: $3 / 35 \mathrm{RA}(8,6 \%)$ and $11 / 27(40,7 \%)$ other sAID, $(p=0.005)$. Among the whole RTX-treated patients, the frequency of RTX-ADA was $2,4 \%$ and $14,7 \%(p=0.003)$ in $R A$ and in other sAID, respectively. Most of the immunized patients experienced delayed infusion reactions (11/14 $[78,5 \%])$. Delayed reactions were observed within the first 15 days after the infusion, and after a median 2 cycles [range; 1-2]. They were mainly rash $(72,7 \%)$, fever $(54.5)$ and/or abdominal pain $(36,3 \%)$. Predictive factors of immunization were a sAID compared to RA $(40,7 \%$ vs $8,6 \%$, $\mathrm{p}=0.005)$, and young age (50.5 vs 61.5 years, $\mathrm{p}=0.003)$. Neither hypergammaglobulinemia, rheumatoid factor, disease activity, nor associated immunosuppressive therapy were associated with RTX-ADA. Among 23 tested patients with SLE or pSS, anti-SSA antibodies tended to be more frequent in immunized patients than non immunized $(9 / 10(90.0 \%)$ vs. $8 /$ $13(61.5 \%), p=0.18)$. Three pSS patients immunized against RTX were treated with OFA because of associated cryoglobulinemic vasculitis or MALT lymphoma. All 3 experienced complete remission of their disease. Relapse occurred in 2 patients, one with MALT lymphoma after 14 months, one with cryoglobulinemic vasculitis after 10 months and were retreated successfully with OFA. No adverse events were reported.

Conclusion: Our results show that immunization against RTX is more frequent in other sAID than in RA. Testing for ADA must be performed in patients with infusion reactions. Patients immunized to RTX might be treated efficiently with OFA, which should be further evaluated in SAID.

Disclosure of Interests: Alice Combier: None declared, Gaetane Nocturne: None declared, Julien Henry: None declared, Rakiba Belkhir: None declared, Stephane Pavy: None declared, Xavier Mariette Grant/research support from: Servier, Consultant for: AstraZeneca, Bristol-Myers Squibb, GlaxoSmithKline, Janssen, Pfizer, UCB Pharma, Raphaèle Seror: None declared

DOI: 10.1136/annrheumdis-2019-eular.3343

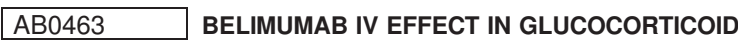 TREATMENT IN SYSTEMIC LUPUS ERYTHEMATOSUS PATIENTS}

Marta De la Rubia Navarro ${ }^{1}$, Susana Cerdá Checa ${ }^{2}$, Jose Ivorra Cortés ${ }^{1,2}$, Elena Grau García ${ }^{1}$, Cristina Alcañiz Escandell ${ }^{1}$, Inmaculada Chalmeta Verdejo ${ }^{1}$, Jorge Juan Fragio-Gil ${ }^{1}$, Roxana Gonzalez Mazario ${ }^{1}$, Luis Gonzalez Puig ${ }^{1}$, Isabel Martínez Cordellat ${ }^{1}$, Rosa Negueroles Albuixech ${ }^{1}$, Jose Eloy Oller Rodríguez ${ }^{1}$, Francisco Miguel Ortiz Sanjuan ${ }^{1}$, Cristobal Pávez Perales ${ }^{1}$, Elvira Vicens Bernabeu ${ }^{1}$, Carmen Nájera Herranz ${ }^{1}$, Inés Cánovas Olmos ${ }^{1}$, Jose Andrés Román Ivorra ${ }^{1,2}$. ${ }^{1}$ Rheumatology Department. HUP La Fe, Valencia, Spain; ${ }^{2}$ Medical School. UCV, Valencia, Spain

Background: Systemic lupus erythematosus (SLE) is an autoimmune chronic disease produced by aberrant immunological response that consequently, causes a widespread organic damage. Treatment leads to regulating this disrupted immunological response. As a result, in 2011 Belimumab was approved for adults patients diagnosed with SLE, what is a monoclonal human antibody whose target is a B-lymphocyte stimulator (BLyS), a protein involved in the disease pathogeny.

Objectives: To evaluate the glucocorticoesteroid dose variation in adult patients with systemic lupus erythematosus during Belimumab IV treatment. Methods: Retrospective, observational study that includes patients diagnosed with SLE according to SLICC 2012 criteria, who are treated with Belimumab IV. Treatment has been administrated as an initial dose: 10 $\mathrm{mg} / \mathrm{kg}$ every 14 days and then, a maintenance dose: $10 \mathrm{mg} / \mathrm{kg}$ every 28 days. Data form serological profile, clinical manifestations at diagnoses and at the onset of treatment, existence of comorbidities or other diseases, concomitant therapy directed to the main disease or to the complications that came from the disease, non administration causes and definitive treatment discontinuation were collected from July 2012 until December 2018.

Results: A total of 19 patients (94.74\% women) with 28 years old (Q1 $14, \mathrm{Q} 3$ 31.82) as a median age at diagnosis and 11 (Q1 6.5, Q3 20) years since disease diagnosis were included. Follow up mean was 29 (Q1 7.5, Q3 37) months.

Regards to concomitant therapies, 5 patients $(26.31 \%)$ were treated with Azatioprine and 3 patients with Methotrexate (15.79\%). At the onset of biological therapy, 17 patients were treated with glucocorticoids, at a dose of $10 \mathrm{mg}$ (Q1 9.38, Q3 10.63). At the end of follow up, 18 patients $(94.73 \%)$ were treated with corticoid and the mean dose was $8.75 \mathrm{mg}$ (Q1 8.75, Q3 8.75).

Table 1. Characteristics of patients on bela.

\begin{tabular}{|c|c|c|c|c|c|c|c|c|}
\hline ID & $\begin{array}{l}\text { Age at SLE } \\
\mathrm{dx}\end{array}$ & Race & $\begin{array}{l}\text { LN } \\
\text { class }\end{array}$ & $\begin{array}{c}\text { Time to KT } \\
\text { (yrs) }\end{array}$ & $\begin{array}{l}\text { Type } \\
\text { KT }\end{array}$ & Induction & Reason for conversion & $\begin{array}{l}\text { Immunosuppressive regimen before } \\
\text { conversion }\end{array}$ \\
\hline $\bar{A}$ & 16 & Black & IV, VI & 13 & DDKT & ATG & Non-adherence & TAC, MMF \\
\hline B & 30 & Asian & & 2 & LRKT & ATG & $\begin{array}{c}\text { Mod IFTA \& } \\
\text { Arteriosclerosis }\end{array}$ & TAC, MPA, PRED \\
\hline C & 18 & White & $\mathrm{IV}, \mathrm{V}$ & 23 & DDKT & ATG & Cortical necrosis & CYC, MMF, PRED \\
\hline D & 19 & Black & V & 9 & LUKT & ATG & CNI side effects & TAC, MPA, PRED \\
\hline $\mathrm{E}$ & 22 & Asian & & 5 & LRKT & ATG & CNI side effects & TAC, MMF, PRED \\
\hline $\mathrm{F}$ & 18 & Black & V & 17 & DDKT & Alemtuzumab & CNI side effects & TAC, MMF, PRED \\
\hline G & 25 & $\begin{array}{c}\text { White } \\
\text { (Hispanic) }\end{array}$ & III, IV & 23 & DDKT & Basiliximab & TMA (biopsy) & TAC, MPA, PRED \\
\hline
\end{tabular}

